Article

\title{
Variation of Microbial Communities in Aquatic Sediments under Long-Term Exposure to Decabromodiphenyl Ether and UVA Irradiation
}

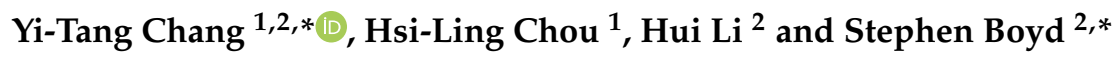 \\ 1 Department of Microbiology, Soochow University, Shilin District, Taipei 11102, Taiwan \\ 2 Department of Plant, Soil and Microbial Sciences, Michigan State University, East Lansing, MI 48824, USA \\ * Correspondence: ytchang@scu.edu.tw (Y.-T.C.); boyds@msu.edu (S.B.); \\ Tel.: +886-2-28819471 (ext. 6862) (Y.-T.C.); +1-517-881-0579 (S.B.)
}

Received: 16 June 2019; Accepted: 6 July 2019; Published: 10 July 2019

\begin{abstract}
Abiotic components create different types of environmental stress on bacterial communities in aquatic ecosystems. In this study, the long-term exposure to various abiotic factors, namely a high-dose of the toxic chemical decabromodiphenyl ether (BDE-209), continuous UVA irradiation, and different types of sediment, were evaluated in order to assess their influence on the bacterial community. The dominant bacterial community in a single stress situation, i.e., exposure to BDE-209 include members of Comamonadaceae, members of Xanthomonadaceae, a Pseudomonas sp. and a Hydrogenophaga sp. Such bacteria are capable of biodegrading polybrominated diphenyl ethers (PBDEs). When multiple environmental stresses were present, Acidobacteria bacterium and a Terrimonas sp. were predominant, which equipped the population with multiple physiological characteristics that made it capable of both PBDE biodegradation and resistance to UVA irradiation. Methloversatilis sp. and Flavisolibacter sp. were identified as representative genera in this population that were radioresistant. In addition to the above, sediment heterogeneity is also able to alter bacterial community diversity. In total, seventeen species of bacteria were identified in the microcosms containing more clay particles and higher levels of soil organic matter (SOM). This means that these communities are more diverse than in microcosms that contained more sand particles and a lower SOM, which were found to have only twelve identifiable bacterial species. This is the first report to evaluate how changes in bacterial communities in aquatic sediment are affected by the presence of multiple variable environmental factors at the same time.
\end{abstract}

Keywords: decabromodiphenyl ether; UVA irradiation; polybrominated diphenyl ethers; sediment heterogeneity; soil organic matter

\section{Introduction}

An ecosystem is a natural community and consists of various biotic and abiotic components that are crosslinked via nutrient cycles and energy flows. The abiotic components in an aquatic system, which include $\mathrm{pH}$, sunlight, turbidity, salinity, available nutrients, dissolved oxygen (DO), soil texture, and soil type, are able to disrupt physiology, behaviors, and interactions of living organisms in the sediment. Aquatic sediment is classified as the largest ecosystem on Earth. Microorganisms play important roles in the biogeochemical cycling of elements, in food webs, and how aquatic ecosystems function in aquatic sediments [1]. These physical/chemical factors are often identified as environmental stressors and influence the growth and development of the biological communities that form the aquatic sediments. Xenobiotic chemicals have been considered as a typical class of environmental stress to ecosystems. Emerging contaminates (ECs) are frequently a major concern due to their persistence 
and toxicity in the environment. One class of ECs of most concern is polybrominated diphenyl ethers (PBDEs), which are widely used as brominated flame retardants (BFR) in industrial products and domestic appliances. PBDE congeners are widely distributed as pollutants in various environments because of the amount of e-waste that is illegally dumped as part of inappropriate waste management. Decabromodiphenyl ether (BDE-209) represents the primary component in many commonly used BFRs and constitutes approximately $83.3 \%$ of the worldwide use of PBDEs. Bioaccumulation of PBDEs can bring about high adverse ecological and human health effects. PBDEs are endocrine disrupting chemicals and have effects on the development of the mammalian reproductive system. Exposure to a high level of PBDE results in mammalian neurotoxicity affecting the developing brain and such exposure can also cause liver carcinogenesis by inducing cytochrome P450s and UDP-glucuronyl transferase [2].

BDE-209 is the most dominant PBDE congener across all contaminated aquatic sediments because of its low bioavailability. The mean concentration of BDE-209 was found at $21-65 \mathrm{ng} / \mathrm{g}$ dry wt. in the surface sediments of the Sydney estuary, Australia. Other PBDEs found at a high concentration included penta-BDEs and octa-BDEs within the range $0.6-2.5 \mathrm{ng} / \mathrm{g}$ dry wt [3]. In China the predominant congener of BDE-209 was found at a concentration of $129.9 \pm 11.1 \mathrm{ng} / \mathrm{g}$ in a surface sediment, and accounted for $96 \%$ of all of the 18 PBDEs present in the sediment [4]. The concentrations of seven PBDE congeners (BDE-47, BDE-99, BDE-100, BDE-153, BDE-154, BDE-183, and BDE-209) ranged from 20 to $78 \mathrm{ng} / \mathrm{g}$ (dry weight) in a South African river. The dominant PBDE congeners in these samples were BDE-209, BDE-99, and BDE-153 at concentrations of 9.4-56, 4-32, and 1-10.6 ng/g, respectively [5]. Commercial BDE-209 is widely present in the soil around electronic waste (e-waste) recycling sites and there appeared to be an explicit transfer of BDE-209 from the e-waste into the environment. For example, the dominant congeners of BDE-209 that were released from CRT TVs and LCD monitors at e-waste recycling companies have been found to contribute between $90.72 \%$ and $93.54 \%$ of the total concentration of PBDEs [6]. The existence of PBDEs in aquatic sediments influence the microbial community and diversity on a case-by-case basis. Highly brominated PBDE congeners are usually more toxic to anaerobic microbes than other PBDEs. For example, BDE-154 has been shown to inhibit bacterial populations more than other PBDEs when $0.1 \mu \mathrm{g} / \mathrm{mL}$ of a number of PBDEs (BDE-47, BDE-99, BDE-100, BDE-153, and BDE-154) were added to an anaerobic bacteria mixed culture [7]. The addition of a high concentration of BDE-209 $(10 \mathrm{mg} / \mathrm{kg})$ seems to increase aerobic microbial diversity, and Firmicutes now become the dominant bacteria when BDE-209 is present [8]. $\varepsilon$-Proteobacteria and Chloroflexi are believed to play important roles in the biodegradation of BDE-209 in the contaminated sediment [9]. It is thus interesting to understand what groups of bacteria are able to tolerate the toxicity of BDE-209 in the aquatic sediment, or develop the ability to degrade this contaminant.

Environmental microorganisms usually are able to show different physiological characteristics under a specific environmental stress in an ecosystem. Irradiation by sunlight, especially UV light, is believed to play an important role in the alterations of sediment bacterial community. UV radiation is reported to damage bacterial DNA structures and lead to genetic mutations. Bacterial transcription, the first step of DNA based gene expression, is terminated directly by UV irradiation [10]. The composition of a bacterial community, the growth of a specific bacteria and bacterial productivity can all be affected by UV [11]. UV is classified into three types, UVA, UVB, and UVC, based on wavelength. Most UVC (below $290 \mathrm{~nm}$ ) is absorbed by the ozone layer and does not reach the Earth's surfaces. UVA rays are able to penetrate the atmosphere and account for up to $95 \%$ of the UV radiation reaching the Earth's surfaces. UVA is present at a relatively equal intensity during daylight throughout the year and is able to easily penetrate clouds. UV photolysis is considered as an important abiotic pathway by which xenobiotic chemicals are broken down via the generation of free radicals [12]. BDE-209 in sediment is gradually debrominated into low-bromine PBDEs because the $\mathrm{C}-\mathrm{Br}$ bonds are attacked by the full wavelength range (300-400 nm) of UVA irradiation [13]. Previous research has focused on the effect of UV on PDBE removal efficiency and the generation of PBDEs byproducts within ecosystems [14-16]. 
For example, the debromination products of BDE-209 in natural matrices (sediment, soil, and sand) exposed to a continuous UVA were nona-PBDEs to tetra-PBDEs [14]. Full wavelength UVA photolysis of BDE-209 (300-400 nm) seems to result in the formation of free radicals and this increases the efficiency of the degradation [15]. However, soil organic matter (SOM) has the ability to strongly absorb BDE-209 or might affect the half-life of free radicals. This influence decreases the consecutive reductive debromination of BDE-209 by UVA irradiation. The half-life of BDE-209 when being photodegraded in sediment containing SOM ( $150 \mathrm{~d}$; TOC $=16.4 \%)$ has been shown to be much longer than when BDE-209 is in the presence of montmorillonite (36 d) and kaolinite (44 d) [16]. However, there is less literature documenting how UVA irradiation affects bacterial activity in sediments as part of affecting ecological services.

The objective of this study is to investigate the influence of long-term UVA irradiation and BDE-209 exposure on the bacterial communities in the aquatic sediments with varying soil compositions. The various bacterial species were identified in terms of their ability to biodegrade PBDEs and their UV resistance. Furthermore, the influence of soil texture and SOM on these bacterial communities was analyzed from a microscale viewpoint. Results from this study provide useful information on how aquatic sediment bacterial communities response to multiple physical/chemical stressors.

\section{Materials and Methods}

\subsection{Chemicals}

BDE-209 with a purity greater than 98\% was used to prepare the BDE-209-contaminated sediment. A standard solution of 24 PBDE congener mixture, dissolved in isooctane-toluene $(8: 2, \mathrm{v} / \mathrm{v})$, was used for the gas chromatography/mass spectrometry (GC/MS) analysis. The congeners imcluded BDE-17, $-28,-47,-49,-66,-71,-77,-85,-99,-100,-119,-126,-138,-153,-154,-156,-183,-184,-191,-196,-197$, $-206,-207$, and -209 . The ${ }^{13}$ C-PBDE internal standards for PBDEs consisted of C13-BDE-28, $-47,-99$, $-100,-153,-154$, and -183 . C13-BDE-138 was used as the recovery standard for the PBDE analysis. All organic solvents, including n-Hexane and acetone, were of GC grade with a purity of $>99.9 \%$. All other chemicals were of reagent grade with a purity of $>99 \%$. The Milli-Q water $(>18 \mathrm{M} \Omega \mathrm{cm})$ was used in this study was obtained from a Millipore water purification system.

\subsection{River Sediments}

PBDE-contaminated river sediments were collected $0-15 \mathrm{~cm}$ in the sediments from drainage basin of the Da-An River in Miaoli County, Taiwan. Each 200-g samples was collected from either below the Yi-Li Bridge (Yi-Li sediment) or from below the Da-An Bridge (Da-An sediment). Figure 1 shows the sampling locations on the Da-An River. Table 1 outlines the physical-chemical characteristics of these sediments. The amount of PBDEs present in the two river sediment samples was estimated by GC-MS analysis (see Section 2.4).

Table 1. Physical-chemical characteristics of Da-An River sediments used in this study ${ }^{1}$.

\begin{tabular}{|c|c|c|c|c|c|c|}
\hline \multirow{2}{*}{$\begin{array}{c}\text { River } \\
\text { Sediment }\end{array}$} & \multirow{2}{*}{$\begin{array}{c}\text { Water Conc. } \\
(\%)\end{array}$} & \multirow{2}{*}{$\begin{array}{c}\text { Organic } \\
\text { Matter (\%) }\end{array}$} & \multirow{2}{*}{ Texture } & \multicolumn{3}{|c|}{ Particle Fraction $^{2}$} \\
\hline & & & & Sand $(\%)$ & Silt (\%) & Clay (\%) \\
\hline Yi-li & 30.0 & 0.474 & Sand & 89.2 & 3.9 & 6.9 \\
\hline Da-an & 30.1 & 0.749 & Silt loam & 28.4 & 50.8 & 20.8 \\
\hline
\end{tabular}

${ }^{1}$ : Measured by the Soil Survey and Testing Center, National Chung-Hsing University, Taichung, Taiwan. ${ }^{2}$ : Ranged particle sizes of the river sediment: clay $<2 \mu \mathrm{m}$; slit $2-10 \mu \mathrm{m}$; sand: $10-2000 \mu \mathrm{m}$. 


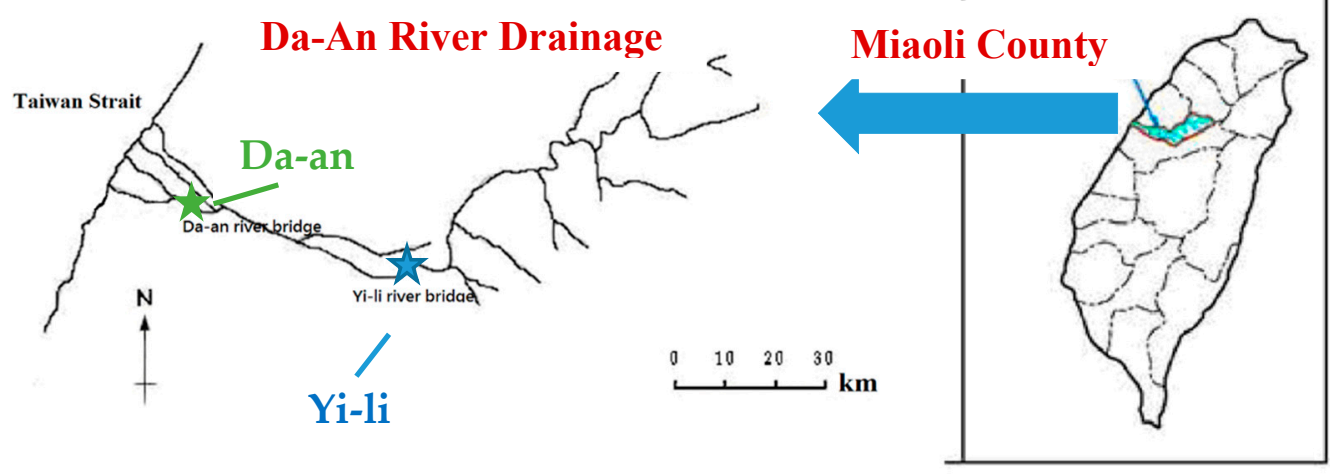

Figure 1. The relative positions in this study used to sample the surface river sediment. The Yi-Li river sediment sample location (blue star mark) and the Da-An River sediment sample location (green stat mark) are located on the Da-An River, Miaoli County, Taiwan.

\subsection{BDE-209-Contaminated Microcosms and Exposure to UVA Irradiation}

Microcosms were setup to simulate the influence of environmental stress on bacterial community in the BDE-209-contaminated sediment ecosystem. 2-L serum bottles contained a solid/water mixture of 10.0-g sediment and 500-mL mineral salt medium (MSB). High amounts of BDE-209 and UVA irradiation are designed as environmental stress in this study. BDE-209-contaminated sediment of Da-an and Yi-Li samples were initially prepared at $20.0 \mathrm{mg} / \mathrm{kg}$, based on the previous study [17]. Microcosms were incubated by the continuing irradiation of narrow-band (365-nm) UV lamp (Philips, The Netherlands) with the light intensity of $1.5 \sim 2.0 \mathrm{mw} / \mathrm{cm}^{2}$ at room temperature for 4 months (120 days). DO in microcosms was always kept above $2.0 \mathrm{mg} / \mathrm{L}$ by a steady aeration of the air-supply equipment during experiments. The group of BDE-209-contaminated microcosms was conducted the same experimental conditions in the dark environment (light intensity $=0 \mathrm{mw} / \mathrm{cm}^{2}$ ). The biotransformation of BDE-209 in the microcosms either in the dark environment or under UVA irradiation was measured with decreased BDE-209 concentration. DNA samples for bacterial community analysis were taken from each of microcosms. Controls of BDE-209-free microcosms under both radiation and no-radiation was conducted.

\subsection{PBDEs Analysis}

PBDEs in the aerobic microcosms were measured by GC-MS after ultrasonic extraction [14]. The solid/water mixture samples were separated into sediment and aqueous solution by centrifugation at $4{ }^{\circ} \mathrm{C}$ and $5000 \mathrm{rpm}$ for $30 \mathrm{~min}$ in a Teflon centrifuge tube (Thermo Scientific ${ }^{\mathrm{TM}}$ Nalgene ${ }^{\mathrm{TM}}$ LabWare, MI, USA). The aqueous solution was discarded, and the solid fractions underwent the ultrasound-assisted extraction. A total of $10 \mathrm{~mL}$ of $\mathrm{n}$-hexane/acetone $(1: 1, \mathrm{v} / \mathrm{v})$ solvent was used to extract PBDEs. Quantification of the PBDEs involved an internal standard method used by the Taiwan Environmental Protection Agency (NIEA M802.00B). This involved the measurement using a GC (Agilent HP 6890, CA, USA)-MS (JEOL MS-700, Tokyo, Japan), a DB-5HT column (Agilent, CA, USA) with helium (99.999\% purity) as a carrier gas at a constant column flow rate $(1 \mathrm{~mL} / \mathrm{min})$. The sample extract $(1-\mu \mathrm{L})$ or a standard solution was injected with solvent to allow analysis of PBDEs. Ionization involved the electron ionization (EI) mode at $38 \mathrm{eV}$. The temperature of the ion source was $320^{\circ} \mathrm{C}$, and the resolving power of the analyzer was 10,000. The MS was operated in the selected ion monitoring (SIM) mode of the GC/MS system with eight descriptors.

\subsection{Bacteria Community Analysis}

The DNA-cloning approach is a good method for realizing species-level identification of bacteria in soil [18]. In this study, molecular cloning was used to identify bacterial species in the microcosms. The experimental procedure is followed by our previous study [19]. Cloning-PCR 
products were sequenced by Genomics Co., Taiwan. All sequences were compared with those of reference microorganisms from GenBank using a BLAST search approach. The $16 \mathrm{~S}$ rDNA sequences closest to the 16S rRNA sequences obtained from the bacteria within the microcosms were retrieved and all sequences were aligned using ClustalX. A phylogenetic tree was constructed by the neighbor-joining method by using Molecular Evolutionary Genetics Analysis 10.1 Beta (https://www.megasoftware.net/). Bootstrap values of $>1500$ (from 5000 replicates) are indicated at the nodes in the phylogenic analysis.

\section{Results}

\subsection{PBDEs Concentrations in River Sediments}

The total concentration of 24 PBDEs in Yi-Li and Da-An sediments were measured at $38 \mathrm{ng} / \mathrm{kg}$ and $39 \mathrm{ng} / \mathrm{kg}$, respectively. BDE-209 manifested the highest concentration in both samples, $32.6 \mathrm{ng} / \mathrm{kg}$ in the Yi-Li sediment and $35.8 \mathrm{ng} / \mathrm{kg}$ in the Da-An sediment, which account for $84 \%$ and $89 \%$ of the total amount of the 24 PBDEs, respectively. The second highest level of PBDE congeners in the two samples were found to be BDE-207 and BDE-206. Figure 2 shows the distribution of the various PBDEs excluding BDE-209 in the Yi-Li and Da-An sediments. Some PBDEs congeners were undetectable, namely BDE-49, BDE-66, BDE-77, BDE-126, and BDE-156 in the Yi-Li sediment and BDE-77 and BDE-85 in the Da-An sediment.
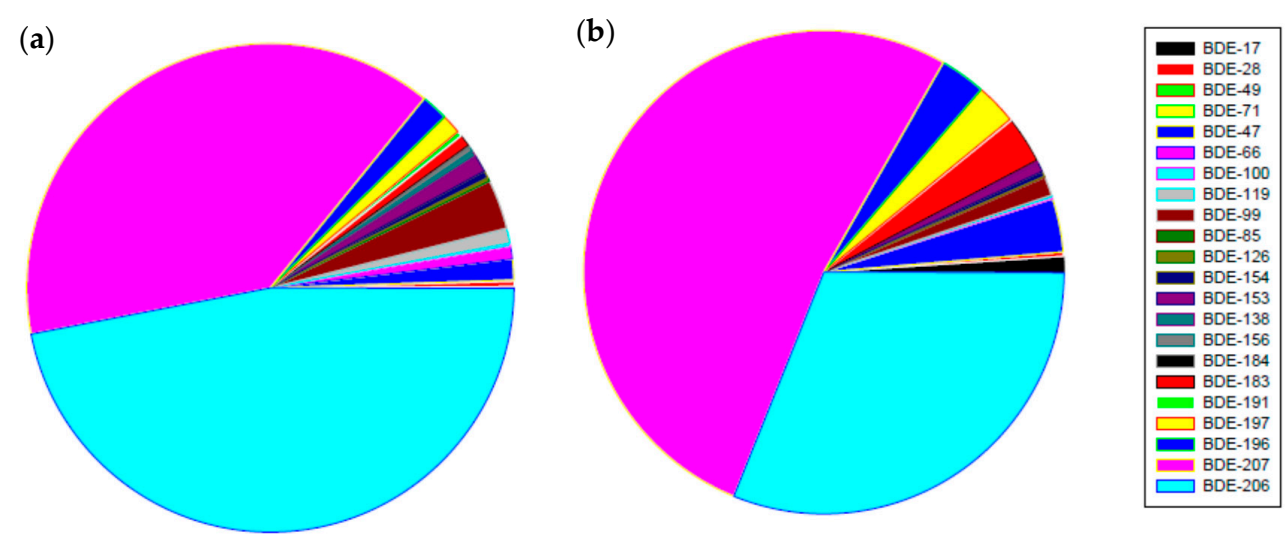

Figure 2. The percentage of total amounts of 23 PBDEs in the sediment samples (except BDE-209): (a) Yi-Li sediment (total 22 PBDEs); (b) Da-An sediment (total 19 PBDEs).

\subsection{Bacterial Communities of Microcosms Containing BDE-209-Contaminated Yi-Li Sediment}

Figure 3 shows the phylum-level analysis of the bacterial communities present in the BDE-209-contaminated Yi-Li microcosms. Figure S1 shows a phylogenetic tree of the cloned 16S rRNA sequences of the bacterial populations present in the Yi-Li microcosms with/without the UVA irradiation. Six phyla that are often found in a soil environment can be identified in the dark microcosm. The dominant bacteria are Proteobacteria $(72.06 \%)$, including $\beta$-Proteobacteria $(53.47 \%)$ and $\gamma$-Proteobacteria (18.59\%). Other four phyla are also present and make up the remaining $27.94 \%$, these are Acidobacteria, Actinobacteria, the CFB group bacteria, and Firmicutes. Six phyla can also be detected in the UV-irradiated microcosm, but there are two new phyla present; these are $\alpha$-Proteobacteria $(9.80 \%)$ and $\delta$-Proteobacteria (7.84\%); furthermore, the Actinobacteria and Firmicutes have disappeared. Table 2 shows the genus-level analysis of the bacteria in the BDE-209-contaminated Yi-Li sediment microcosms. Figure S1 shows twelve distinct bacterial species can be identified in the dark environment; similarly, twelve bacterial species can be identified after the UVA irradiation for 3 months. The percentages of Methyloversatilis sp. (23.25\%-23.53\%), which is $\beta$-Proteobacteria, Acidobacteria bacterium $(9.30 \%-9.80 \%)$, which is an Acidobacteria and Ferruginibacter sp. (6.97\%-7.84\%), which is a CFB group bacteria, are similar in both the dark microcosm and the UVA-irradiated microcosms. Other dominant bacterial species $(\geq 5 \%)$ that were identified as present in the dark microcosm were Comamonadaceae bacterium 
(11.62\%), Acidovorax sp. (9.30\%), Xanthomonadaceae bacterium (9.30\%), Pseudomonas sp. (6.97\%), Propionibacterium sp. (6.97\%). By way of contrast, in the UVA-irradiated microcosm, Sediminibacterium ginsengisoli (11.76\%), Terrimonas ferruginea (9.80\%), Anaeromyxobacter sp. (5.88\%), Lishizhenia sp. (5.88\%), and Caedibacter sp. $(5.88 \%)$ were dominant.

(a)

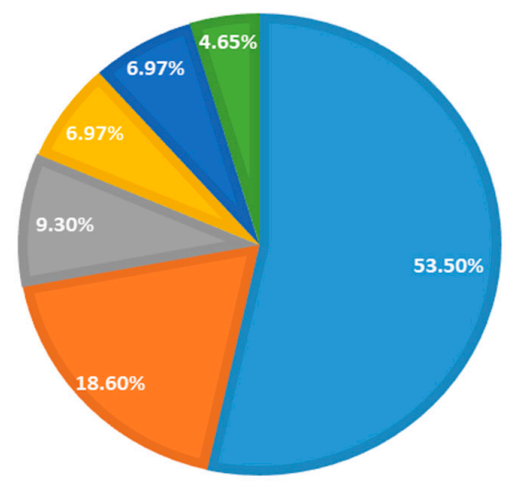

(b)

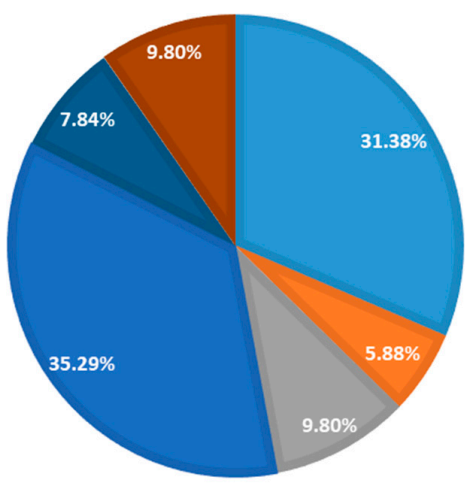

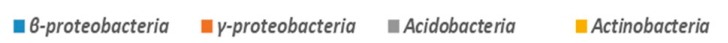

$$
\begin{aligned}
& \text { - CFB group bacteria = Firmicutes } \delta \text {-proteobacteria } \quad \alpha \text {-proteobacteria }
\end{aligned}
$$

Figure 3. The phylum-level bacterial community as percentages present in the BDE-209-contaminated Yi-Li microcosms. (a) In the dark environment; (b) in the UVA irradiated environment.

Table 2. Bacteria at species level identified in the BDE-209-contaminated Yi-Li microcosms.

\begin{tabular}{|c|c|c|c|c|c|}
\hline \multicolumn{3}{|c|}{ Microcosm in the Dark Environment } & \multicolumn{3}{|c|}{ Microcosm in the UVA Irradiation } \\
\hline No. & Bacterial Strains & Proportion $^{1}(\%)$ & No. & Bacterial Strains & Proportion $^{2}(\%)$ \\
\hline 1 & Methyloversatilis sp. & 23.25 & 1 & Methyloversatilis sp. & $23.53^{3}$ \\
\hline 3 & Acidovorax sp. & 9.30 & 3 & Acidobacteriaceae bacterium & 9.80 \\
\hline 4 & Xanthomonadaceae bacterium & 9.30 & 4 & Terrimonas ferruginea & 9.80 \\
\hline 5 & Acidobacteria bacterium & 9.30 & 5 & Ferruginibacter alkalilentus & 7.84 \\
\hline 7 & Propionibacterium sp. & 6.97 & 7 & Alpha proteobacterium & 5.88 \\
\hline 8 & Ferruginibacter sp. & 6.97 & 8 & Lishizhenia sp. & 5.88 \\
\hline 9 & Clostridium akagii & 4.65 & 9 & Caedibacter sp. & 5.88 \\
\hline 10 & Alcaligenes sp. & 4.65 & 10 & Rhodocyclaceae bacterium & 3.92 \\
\hline 11 & Hydrogenophaga sp. & 4.65 & 11 & Rhizobiales bacterium & 3.92 \\
\hline 12 & Pseudoxanthomonas sp. & 2.32 & 12 & Comamonas sp. & 3.92 \\
\hline
\end{tabular}

\subsection{Bacterial Communities of Microcosms Containing BDE-209-Contaminated Da-An Sediment}

Figure 4 shows the phylum-level bacterial communities present in the BDE-209-contaminated Da-An microcosms. Figure S2 shows a phylogenetic tree of the cloned 16S rRNA sequences of the bacterial populations in the Da-An microcosms with/without UVA irradiation. Six phyla were identified in the dark microcosm. The dominant bacteria were Proteobacteria $(62.70 \%)$, including $\alpha$-Proteobacteria $(10.35 \%), \beta$-Proteobacteria $(42.00 \%)$, and $\gamma$-Proteobacteria $(10.35 \%)$. The percentages of other phyla present were CFB group bacteria (18.33\%), Acidobacteria (15.20\%), and Firmicutes (3.50\%). Four phyla found in the UV-irradiated microcosm. There was a significant increase in the CFB group bacteria (49.12\%) and $\alpha$-Proteobacteria (37.88\%) compared to the dark control after long-term UVA irradiation for 4 months. Table 3 shows the bacteria present in the BDE-209-contaminated Da-An sediment microcosms at the genus-level. The bacterial community consisted of abundant 
seventeen bacterial species when the dark environment was examined and nine abundant bacterial species after the UVA irradiation. Four bacterial species, namely Acidobacteria bacterium, Flavobacteriia bacterium (Flavisolibacter sp.), Xanthomonadaceae bacterium (Xanthomonas sp.), and Hyphomicrobium sp. (Hyphomicrobium zavarzinii) were identified in both microcosms. Nevertheless, the percentages of each bacterial species did differ significantly between the dark microcosm and the UVA irradiation microcosm. For example, the percentage of Acidobacteria bacterium was $15.00 \%$ in the dark microcosm and this was found to have decreased to $5.88 \%$ in the UVA-irradiated microcosm. The percentage of Flavobacteriia bacterium was $3.33 \%$ in the dark microcosm and this was increased to $35.29 \%$ in the UVA-irradiated microcosm. The same trend was present for the Hyphomicrobium sp., which increased from $3.33 \%$ in the dark microcosm to $13.73 \%$ in the UVA-irradiated microcosm. The other major bacterial species ( $\geq 5 \%$ ) identified were Gemmatimonas sp. (15.00\%), Comamonas sp. (10.00\%), Azoarcus sp. (10.00\%), Methylibium sp. (8.33\%), Pseudoxanthomonas sp. $(5.00 \%)$, and Rhodocyclaceae bacterium $(5.00 \%)$ in the dark microcosm; on the other hand, the two other species in the UV-irradiation microcosm were Sphingobacteria bacterium (9.82\%), and Sphingomonas sp. (5.88\%).

(a)

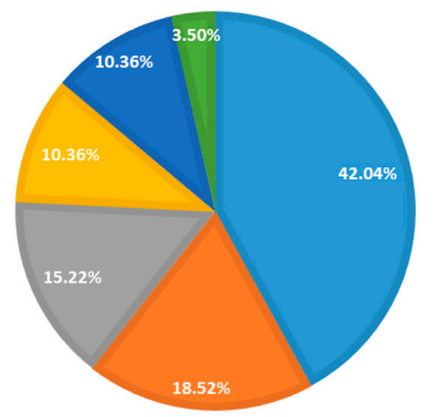

(b)

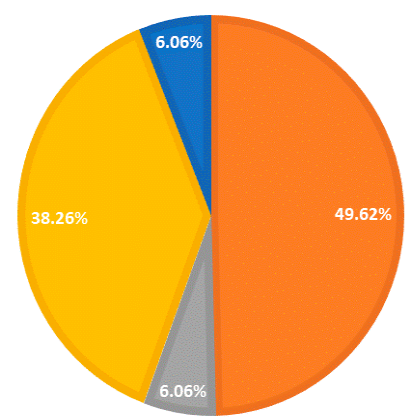

$$
\begin{aligned}
& \text { - B-proteobacteria }=\text { CFB group bacteria }=\text { Acidobacteria } \\
& =\alpha \text {-proteobacteria } \quad v \text {-proteobacteria }=\text { Firmicutes }
\end{aligned}
$$

Figure 4. The phylum-level bacterial community as percentages present in the BDE-209-contaminated Da-An microcosms: (a) In the dark environment; (b) in the UVA irradiation environment.

\begin{tabular}{|c|c|c|c|c|c|}
\hline \multicolumn{3}{|c|}{ Microcosm in the Dark Environment } & \multicolumn{3}{|c|}{ Microcosm in the UVA Irradiation } \\
\hline 1 & Acidobacteria bacterium & 15.00 & 1 & Flavisolibacter sp. & $35.29^{6}$ \\
\hline 3 & Comamonas sp. & 10.00 & 3 & Alpha proteobacterium & 13.73 \\
\hline 4 & Azoarcus sp. & $10.00^{4}$ & 4 & Sphingobacteria bacterium & 9.82 \\
\hline 5 & Methylibium sp. & $8.33^{5}$ & 5 & Acidobacteria bacterium & 5.88 \\
\hline 7 & Rhodocyclaceae bacterium & 5.00 & 7 & Sphingomonas sp. & 5.88 \\
\hline 8 & Lautropia sp. & 3.33 & 8 & Parvibaculum sp. & 3.92 \\
\hline 9 & Firmicutes bacterium & 3.33 & 9 & Terrimonas sp. & 3.92 \\
\hline 10 & Hydrogenophaga sp. & 3.33 & & & \\
\hline 11 & Pseudomonas sp. & 3.33 & & & \\
\hline 12 & Alpha proteobacterium & 3.33 & & & \\
\hline 16 & Xanthomonas sp. & 1.66 & & & \\
\hline 17 & Nitrosomonas sp. & 1.66 & & & \\
\hline
\end{tabular}

Table 3. Bacteria at species level identified in the BDE-209-contaminated Yi-Li microcosms.

1: Proportion is defined as the percentage of value 60 white colonies divided by bacteria-identified colonies.

2: Proportion is defined as the percentage of value 51 white colonies divided by bacteria-identified colonies.

${ }^{3}$ : Including 5.00\% Gemmatimonadetes bacterium. ${ }^{4}$ : Including 3.33\% Azoarcus indigens. ${ }^{5}$ : Include $3.33 \%$ Methylibium fulvum. ${ }^{6}$ : Include 7.84\% Flavisolibacter ginsengiterrae. ${ }^{7}$ : Include 5.88\% Hyphomicrobium denitrificans and 3.92\% Hyphomicrobium facile. 


\section{Discussion}

\subsection{Bacterial Species Involved in PBDE Biodegradation in the Microcosms}

Microbial community structures and their metabolic activities in river sediments were sensitive bioindicators of the existence of environmental stressors in this study. Considering the toxic effects of BDE-209 alone on the bacterial community in dark microcosms, major bacterial groups present include at the Phylum/Class level were $\beta$-Proteobacteria $(42.00 \%-53.47 \%), \gamma$-Proteobacteria $(10.53 \%-18.59 \%)$, CFB group bacteria (6.97\%-18.5\%), Acidobacteria $(9.30 \%-15.20 \%)$, and Firmicutes $(3.65 \%-4.65 \%)$, while at a Family/Genus level, Acidobacteria bacterium (9.30\%-15.00\%), Comamonadaceae bacterium (including Comamonas sp.) (10.00\%-11.62\%), Xanthomonadaceae bacterium (including Xanthomonas sp.) (1.66\%-9.30\%), Pseudomonas sp. (3.33\%-6.97\%), and Hydrogenophaga sp. (3.33\%-4.65\%) were identified. Previous studies have indicated that the presence of BDE-209 will alter the bacterial community structure. when a soil/water system containing $10 \mathrm{~g}$ of river sediment, $1.0 \mathrm{~g}$ of BDE-209 and $200 \mathrm{of}$ $\mathrm{mL}$ water was incubated under aerobic conditions at $28^{\circ} \mathrm{C}$ for two months, the Phyla Proteobacteria, Planctomycetes, Acidobacteria, Actinobacteria, Chloroflexi, Bacteroidetes, and Firmicutes were detected in the BDE-209-contaminated sediment. At the genus level, Acidobacterium, Hydrogenophaga (H. atypica), Gemmatimonadetes, and a Sphingomonas sp. were found. These findings are similar to the results of the present study [20]. The dominant groups, namely Proteobacteria, Acidobateria, and Firmcutes, including $\gamma$-Proteobacteria, $\beta$-Proteobacteria, $\alpha$-Proteobacteria, Acidobateria, and Clostridia, seem likely to be playing important roles in the degradation of BDE-99 and its intermediate metabolites (PBDEs and OH-PBDEs) [9]. Moreover, the phyla Proteobacteria, Acidobacteria, Bacteroidetes, Chloroflexi, and Firmicutes have been found to dominate e-waste-contaminated river sediments, which are known to contain a mixture of heavy metals, PCBs, and PBDEs (mostly BDE-209). PBDEs degradation in sediment seems to involve various dominant genera, such as Pseudomonas, Burkholderia, Acinetobacter, Sulfuricurvum, Thiobacillus, and Alcanivorax, which are all member of the Proteobacteria [21,22].

Many bacterial species in this study have been reported to have the ability to biodegrade PBDE congeners when these are present in soil/sediment [23-29]. Pseudomonas spp., which are members of the Gram-negative $\gamma$-Proteobacteria; these are present in the dark BDE-209-contaminated microcosms $(6.97 \%$ in the Yi-Li sample and 3.33\% in the Da-An sample). Pseudomonas spp. been shown to have the ability to utilize BDE-209 and other PBDEs as carbon source during in situ bioremediation. Pseudomonas spp. have been found to be the most dominant species in the soil after spiking with BDE-15 in the range of 1-100 $\mathrm{mg} / \mathrm{kg}$ for 180 days [23]. A positive response by the catechol 2,3-oxygenase gene was detected when biodegradation of $25 \mathrm{mg} / \mathrm{kg}$ BDE-209 by Pseudomonas in the various soil slurry microcosms was taking place [24]. Pseudomonas aeruginosa is able to utilize BDE-209 as a sole carbon source and is able to reach its highest degradation efficiency when a ratio of 1:5 BDE-209 and glucose as an extra carbon source are present. The lower brominated products of PBDEs, which include two nona-bromodiphenyl ethers (BDE-208, BDE-207), four octa-bromodiphenyl ethers (BDE-203, BDE-202, BDE-197, BDE-196) and one hepta-bromodiphenyl ethers (BDE-183), were formed during this biodegradation process [25]. A crude enzyme extracted from Pseudomonas aeruginosa was found to contain a mixture of intracellular enzymes and various degradation enzymes that are able to degrade BDE-209 into lower brominated PBDEs and OH-PBDEs; this occurred through debromination and hydroxylation of the aromatic rings [26]. Pseudomonas stutzeri, which was isolated from a PBDE-polluted area, is able to use BDE-47 as a sole source of carbon and was capable of transforming $97.94 \%$ of BDE-47 in two weeks into energy [27]. Pseudomonas putida is able to degrade BDE-47, with up to $49.96 \%$ of $50 \mu \mathrm{g} / \mathrm{L}$ being degraded after 7 days at $150 \mathrm{rpm}$ and incubation at, $30{ }^{\circ} \mathrm{C}$ [28]. Another Pseudomonas putida strain was used for the bioremediation of three PBDE congeners (BDE-47, BDE-15, and BDE-3) and this study used an initial concentration of $2 \mathrm{mg} / \mathrm{L}$. A extra carbon source, such as glucose and biphenyl, was able to play a positive role in promoting the biodegradation of these PBDEs and had no effects on the PBDEs degradation pathways [29].

Comamonadaceae bacteria (including Comamonas spp.) are present in both the Yi-Li sediment $(11.62 \%)$ and the Da-An sediment $(10.00 \%)$ in the dark microcosms; however, it can only be found in the 
UV-irradiated Yi-Li sediment microcosm at a reduced level (3.92\%) and is absent from the UV-irradiated Da-An sediment microcosm. Comamonadaceae are a family of Gram-negative aerobic $\beta$-Proteobacteria. that are known to biodegrade PBDEs when they are in contaminated soils. The Comamonas sp. are is probably involved in helping electron donation to pyruvate in the dark anaerobic microcosms that contains BDE-209-contaminated sediment. Microbial community structure can be altered by the amount of biometabolites present in the system such as tri-BDE congener (BDE-32) and hexa-BDE [30]. Comamonas spp. have been shown to be present in an enriched bacterial culture involving sediment contaminated with BDE-209 and microscale ZVI, which seems to promote the degradation of BDE-209. PBDE congeners, such as nona-BDEs, octa-BDEs, hepta-BDEs, and hexa-BDEs, have been shown to have a synergistic effect on the degradation of PBDEs [31].

On the other hand, Sphingomonas sp. (5.88\%), another group of aerobic gram-negative bacteria, were also detected in the UVA-irradiated Da-An sediment microcosm. Sphingomonas sp. has been shown to have the ability to biodegrading low-brominated PBDEs. Sphingomonas strain SS3 has been shown to aerobically biotransform 4-bromodiphenyl ether and the di-BDE congeners: 4,4' - dihalodiphenyl ethers and 2,4-dihalodiphenyl ethers [32,33]. Sphingomonas sp. PH-07, which was isolated from activated sludge, is capable of biodegrading PBDE congeners such as 4-Bromodiphenyl ether (23\% removal), 2,4-dibromodiphenyl ether (14\% removal), and 4,4'-dibromodiphenyl ether (BDE-15, $8 \%$ removal) when they are present in a $1 \mathrm{~g} / \mathrm{L}$ diphenyl ether solution [34]. A 67\% biodegradation of BDE-209 was found and PBDE intermediates produced (ranging from nona-BDEs to tri-BDEs) when $1 \mathrm{mg}$ BDE-209 was degraded in the presence of a mixture of Sphingomonas sp. PH-07 and $100 \mathrm{mg}$ nano-ZVI over a 20-day period [35].

Another bacterial species Clostridium akagii, has been identified as present in the dark Yi-Li microcosm $(4.65 \%)$. This is a nitrogen-fixing anaerobic bacterium. When a Clostridium sp. is exposed to $1 \mu \mathrm{g} / \mathrm{L}$ BDE-47, it becomes enriched and there is induction of various genes associated with DNA repair, multidrug efflux pumping, bacterial chemotaxis and bacterial motility [36]. A Clostridium sp. has been found to be able to biodegrade BDE-3 when there is co-metabolism with glucose via an anaerobic degradation process. Two biometabolites, diphenyl ether and bromide ions $\left(\mathrm{Br}^{-}\right)$were detected during the debromination [37].

\subsection{The Effects UVA Irradiation and the Presence of of BDE-209 on the Bacterial Communities}

Bacterial groups present in the microcosms changed when they were continuously exposed to more than one environmental stressor, namely a high exposure to BDE-209 and long-term UVA irradiation. There was a synergistic effect that apparently brought about an alteration in the structure of the bacterial community. At the Phylum/Class level, the CFB bacteria group ( $35.28 \%-49.12 \%)$, Acidobacteria (5.88\%-9.80\%), and $\gamma$-Proteobacteria (5.88\%-6.00\%) were now present. At the Family/Genus level, Acidobacteria bacterium (a member of the Acidobacteriaceae) and a Terrimonas sp. (Terrimonas ferruginea) $(3.92 \%-9.80 \%)$ were present in all of the microcosms; we suggest that this is because these organisms have a broad range of physiological functions in both PBDE biodegradation and in resistance to UVA irradiation. For example, Acidobacteria bacterium is widely found in a variety of environments including soil (sediment), hot springs and oceans, which suggests both important ecological roles and extensive metabolic versatility. Acidobacterium bacterium is able to tolerate in environment a wide range of pollutant including aromatic pollutants, such as PCBs and petroleum compounds, linear alkylbenzene sulfonate, and p-nitrophenol; it seems likely that they are involved in the degradation of these organic pollutants under such circumstances [38]. Homologs of genes encoding various repair proteins that are known to be involved in protecting against UV irradiation damage, such as ChoIII and UvrA, have been identified in Acidobacterium [39]. Terrimonas sp., a Gram-negative strictly aerobic bacterium has been found in polluted farmland soil, and in bulking sludge from a wastewater treatment plant. Biodegradation of aromatic compounds has been reported for this group of bacteria and this suggest that biodegradation of PBDEs by these bacteria might be possible. Terrimonas sp. (Terrimonas ferruginea) is an aerobic Gram-negative bacterium and potentially has been associated with anthracene 
biodegradation at a municipal solid waste composting site [40]. Terrimonas spp. are members of the CFB group, which is known to contain many strains that are highly resistant to solar radiation [41]. It has also been shown that biodegradation of methyl tert-butyl ether (MTBE) as a sole carbon and energy source occurred in the presence of a bacterial community largely made up of members of the phylum Acidobacteria and the genus Terrimonas [42].

The dominant bacterial species present in these microcosms seem to have both a high tolerance for UV irradiation as well as the ability to bring about PBDE biodegradation. Methylobacterium, a facultative methylotrophic bacterium that is commonly in soil and river sediments, had the highest percentage presence in our stressed microcosms (23.53\% in the Yi-Li microcosm). Methylobacterium is defined as a "radioresistant bacteria" which means that it is resistant to high levels of UV radiation. The genera representatives of radioresistant bacteria genera within the Methylobacterium include Deinococcus, Rubrobacter, Methylobacterium, Kocuria, Bacillus, and Thermococcus. These bacterial strains are resistant to high levels of ultraviolet radiation (up to $5000 \mathrm{~J} / \mathrm{m}^{2}$ ) [43,44]. Radioresistant bacteria usually contain enzymes that are able to repair the damaged DNA present after irradiation and thus can survive high levels of radiation. Methylobacterium can be inferred to have the ability to biodegrade PBDEs because they also have the highest percentage presence in the dark microcosm (23.25\% in the Yi-Li microcosm). Relevant to this, a Methyloversatilis sp. has been reported to be capable of the anaerobic dehalogenation of organic halogenated compounds such as PBDEs and dichloromethane [17,45]. A Methyloversatilis sp. has been found in microcosms that might be producing trichloroethylene (TCE)-degrading enzymes, which could be involved in various TCE co-metabolic processes [46]. In addition to the above, Flavisolibacter sp., a Gram-staining-negative rod-shaped bacterium, seems to play an important role in the bacterial communities that are resistant to UVA-irradiation. The percentage of Flavisolibacter reached $35.29 \%$ in the UV-irradiated microcosm. In this context, previous studies have indicated Flavisolibacter tropicus is resistant to low levels of radiation (3 kGy gamma radiation) [47]. This Flavisolibacter tropicus strain was isolated from a soil sample and had genes present in its genome that are relevant to radiation resistance, such as excinuclease UvrABC complex and UvdE [48]. Flavisolibacter has been reported to be an important and sensitive indicator of the presence of a range of POPs in soils, such as carbamazepine and triclosan $[9,49]$. Furthermore, it has been shown that atrazine is biodegraded by Flavisolibacter during the vermicomposting process [50].

\subsection{The Influence of Sediment Heterogeneity on the Bacterial Community}

Microbial activity uses the different sedimentary structures present in a sediment as specific ecological niches. Any bacterial taxa will have a spatially heterogeneous distribution involving distinct micro-environments within a given aquatic sediment. Sediment heterogeneity, including soil texture and the pore size distribution, are able to indirectly influence the dynamics of nutrient cycling and this occurs by restricting bacterial movement; this will result in the detection of a range of different bacterial species within a given bacterial community. For example, Gemmatimonadales prefers coarse silts $(20-63 \mu \mathrm{m})$, while Actinobacteria and Nitrosospira prefer fine silts $(2-20 \mu \mathrm{m})$; on the other hand, Planctomycetales is found in the clay fraction (clay $<2 \mu \mathrm{m}$ ) [48]. The composition of the Yi-Li sediment is made up for the most part of larger sand particles $(89.2 \%)$ and silt and clay only contribute $3.9 \%$ and $6.9 \%$. respectively. The major bacterial groups present in the dark Yi-Li microcosm includes Methyloversatilis sp. of the $\beta$-Proteobacteria (23.25\%); Comamonadaceae bacterium of the $\beta$-Proteobacteria (11.62\%); Acidovorax sp. of the $\beta$-Proteobacteria (9.30\%); Xanthomonadaceae bacterium of the $\gamma$-Proteobacteria (9.30\%); Acidobacteria bacterium of the Acidobacteria (9.30\%); Pseudomonas sp. of the $\gamma$-Proteobacteria (6.97\%); Propionibacterium sp. of the Actinobacteria (6.97\%); and Ferruginibacter sp. of the CFB group bacteria (6.97\%). These bacteria seem to be taking advantage of the sand size particle fraction as suggested by previous studies. Larger particle sizes (sand) seem to be dominated by Proteobacteria [49]. Bacteroidetes and Proteobacteria have often been found in the sand-sized fraction $(63-2000 \mu \mathrm{m})$ that contains free particulate organic matter (POM), which is a source of nutrients for both soil microorganisms and aquatic microorganisms [51]. 
On the other hand, the Da-An sediment has a high silt content of $50.8 \%$ and the clay content in the Da-An sediment reaches $20.8 \%$, which is three-time higher than that of the Yi-Li sediment. The presence of more clay particles in the sediment ecosystem seems to result in an increase in bacterial biodiversity. Seventeen bacterial species were present in the dark Da-An microcosm compared to only twelve bacterial species in the dark Yi-Li microcosm. Furthermore, the bacterial groups present in the dark Da-An microcosm are different to those in Yi-Li microcosm and include an Acidobacteria bacterium, a member of the Acidobacteria (15.00\%); a Gemmatimonas sp. a member of the CFB group of bacteria (15.00\%); a Comamonas sp., a member of the $\beta$-Proteobacteria (10.00\%); an Azoarcus sp., a member of the $\beta$-Proteobacteria $(10.00 \%)$; a Methylibium sp., a member of the $\beta$-Proteobacteria $(8.33 \%)$; a Pseudoxanthomonas sp., a member of the $\gamma$-Proteobacteria (5.00\%); and a Rhodocyclaceae bacterium, a member of the $\beta$-Proteobacteria (5.00\%). Clay particles with a size range of 0.1 to $2 \mu \mathrm{m}$ seem to have a dominant role in determining what microbes are present under aerobic, facultative and anaerobic growth conditions. Clay particles are able to aggregate together, and this allows the formation of biofilm formed from extracellular polysaccharides (EPSs). Bacteria are often found embedded in the biofilm surrounding clay particles and become encapsulated in the clay, residing preferentially in small pores. The Holophaga/Acidobacterium division of Acidobacteria has been shown to be dominant when smaller size fractions (silt and clay) form a soil [52].

Another possible explanation for the changes that occurs in bacterial communities when sediments change can be ascribed to soil organic matter (SOM) content of the sediment. SOM is a critical factor and can have a strong influence on the microbial biomass and its community structure. The SOM is made up of carbon-organic compounds. This are able to contribute carbon, oxygen, hydrogen, and nitrogen to bacteria, which will stimulate biological growth; SOM is able to improve both the physical and chemical characteristics of a sediment. The SOM present in a sediment based ecological system is able to be composted by the microbes present in the environment [53]. Most SOM is processed by heterotrophic bacteria and these use the SOM's organic carbon content as a nutrient source and as an energy source; this in particular involves soil respiration and nitrogen mineralization. High levels of SOM in a sediment usually result in increased microbial activity and this can enhance biodiversity $[54,55]$. A low SOM content will reduce the microbial population present in a given soil [56]. In this study, the SOM content of the sediments can be seen to be related to the biodiversity of the bacterial community present within that soil. The microcosm with the higher SOM content $(0.749 \%)$ was the Da-An sediment and this has much greater biodiversity (17 bacterial species), compared to the Yi-Li sediment with a lower SOM content $(0.474 \%)$, which has a lower biodiversity (12 bacterial species).

\section{Conclusions}

Environmental stress caused by physical and chemical factors results in alteration to a bacterial community that are related to the specific physiological characteristics of a given aquatic ecosystem. Bacterial species capable of PBDE biodegradation were able to be identified in the aquatic sediments investigated here after adding a high level of BDE-209. The introduction of this stressor resulted in a number of aerobic/anaerobic bacteria gaining a selective advantage; specifically, Comamonadaceae, Pseudomonas, Sphingomonas, and Clostridum were identified during the present study. The synergy between long-term exposure to UVA irradiation and contamination of soil by BDE-209 seems to inhibit the growth of some bacteria. Acidobacteria and Terrimonas are the dominant bacterial groups in the presence of UVA irradiation. Methloversatilis sp. and Flavisolibacter sp., are UV-resistant and radioresistant bacteria, are major species present when there is biodegradation of PBDEs in the presence of UVA irradiation.

Supplementary Materials: The following are available online at http://www.mdpi.com/2071-1050/11/14/3773/s1, Figure S1: A phylogenetic tree of the cloned 16S rRNA sequences obtained from the bacterial populations present in the Yi-Li microcosms with/without the UVA irradiation, Figure S2: A phylogenetic tree of the cloned 16S rRNA sequences obtained from the bacterial populations present in the Da-An microcosms with/without the UVA irradiation. 
Author Contributions: Conceptualization, Y.-T.C.; Methodology, H.-L.C. and Y.-T.C.; Writing-original draft preparation, Y.-T.C. and H.-L.C.; writing-review and editing, H.L. and S.B.; Project administration, Y.-T.C.; Funding acquisition, Y.-T.C.

Funding: This work was supported by the Taiwan MOST projects, grant number MOST102-2221E-031-001-MY2; MOST108-2918-I-031-001.

Acknowledgments: Part of the results/discussion was presented at the 6th International Conference on Challenges in Environmental Science \& Engineering (CESE-2013) in 2013 and the 5th International Ecological Sustainability: Engineering Change (EcoSummit-2016) in 2016.

Conflicts of Interest: The authors declare no conflict of interests.

\section{References}

1. Smith, P.; Cotrufo, M.F.; Rumpel, C.; Paustian, K.; Kuikman, P.J.; Elliott, J.A.; McDowell, R.; Griffiths, R.I.; Asakawa, S.; Bustamante, M.; et al. Biogeochemical cycles and biodiversity as key drivers of ecosystem services provided by soils. Soil 2015, 1, 665-685. [CrossRef]

2. Lee, E.; Kim, T.H.; Choi, J.S.; Nabanata, P.; Kim, N.Y.; Ahn, M.Y.; Jung, K.K.; Kang, I.H.; Kim, T.S.; Kwack, S.J.; et al. Evaluation of liver and thyroid toxicity in Sprague-Dawley rats after exposure to polybrominated diphenyl ether BDE-209. J. Toxicol Sci. 2010, 35, 535-545. [CrossRef] [PubMed]

3. Drage, D.; Mueller, J.F.; Birch, G.; Eaglesham, G.; Hearn, L.K.; Harrad, S. Historical trends of PBDEs and HBCDs in sediment cores from Sydney estuary, Australia. Sci. Total Environ. 2015, 512-513, 177-184. [CrossRef] [PubMed]

4. Wu, Q.; Liu, X.; Liang, C.; Leung, J.Y.S.; Li, H.; Chen, S.; Mai, B.; Miao, S.; Chen, Y.; Wu, Z.; et al. Historical trends and ecological risks of polybrominated diphenyl ethers (PBDEs) and alternative halogenated flame retardants (AHFRs) in a mangrove in South China. Sci. Total Environ. 2017, 599, 181-187. [CrossRef] [PubMed]

5. Chokwe, T.B.; Magubane, M.N.; Abafe, O.A.; Okonkwo, J.O.; Sibiya, I.V. Levels, distributions, and ecological risk assessments of polybrominated diphenyl ethers and alternative flame retardants in river sediments from Vaal River, South Africa. Environ. Sci. Pollut. Res. 2019, 26, 7156-7163. [CrossRef] [PubMed]

6. Yu, D.; Duan, H.; Song, Q.; Liu, Y.; Li, Y.; Li, J.; Shen, W.; Luo, J.; Wang, J. Characterization of brominated flame retardants from e-waste components in China. Waste Manag. 2017, 68, 498-507. [CrossRef] [PubMed]

7. Yen, J.H.; Liao, W.C.; Chen, W.C.; Wang, Y.S. Interaction of polybrominated diphenyl ethers (PBDEs) with anaerobic mixed bacterial cultures isolated from river sediment. J. Hazard. Mater. 2009, 165, 518-524. [CrossRef]

8. Wu, P.; Wang, Y.-S.; Sun, C.-C.; Sun, F.-L.; Wang, Y.-T. Microbial community shift with decabromodiphenyl ether (BDE 209) in sediments of the Pearl River estuary, China. Biologia 2013, 68, 788-796. [CrossRef]

9. Ma, W.; Yan, Y.; Ma, M.; Zhang, Y.; Cheng, X. Migration and biodegradation of BDE-99 in different river-based natural groundwater recharge modes with treated municipal wastewater. Process Saf. Environ. 2016, 104, 531-540. [CrossRef]

10. Rastogi, R.P.; Kumar, R.A.; Tyagi, M.B.; Sinha, R.P. Molecular mechanisms of ultraviolet radiation-induced DNA damage and repair. J. Nucleic Acids 2010, 2010, 592980. [CrossRef]

11. Hunting, E.R.; White, C.M.; van Gemert, M.; Mes, D.; Stam, E.; van der Geest, H.G.; Kraak, M.H.; Admiraal, W. UV radiation and organic matter composition shape bacterial functional diversity in sediments. Front. Microbiol. 2013, 4, 317. [CrossRef] [PubMed]

12. Steinberg, C.E.W.; Paul, A. Photolysis. In Encyclopedia of Ecology; Jørgensen, S.E., Fath, B.D., Eds.; Elsevier: Amsterdam, The Netherland, 2008; Volume 1, pp. 2724-2732, ISSN 978-0-08-045405-4.

13. Pan, Y.; Tsang, D.C.W.; Wang, Y.; Li, Y.; Yang, X. The photodegradation of polybrominated diphenyl ethers (PBDEs) in various environmental matrices: Kinetics and mechanisms. Chem. Eng. Sci. 2016, 297, 74-96. [CrossRef]

14. Söderström, G.; Sellström, U.; de Wit, C.A.; Tysklind, M. Photolytic debromination of decabromodiphenyl ether (BDE 209). Environ. Sci. Technol. 2004, 38, 127-132. [CrossRef] [PubMed]

15. Suh, Y.-W.; Buettner, G.R.; Venkataraman, S.; Treime, S.E.; Robertson, L.W.; Ludewig, G. UVA/B-Induced formation of free radicals from decabromodiphenyl ether. Environ. Sci. Technol. 2009, 43, 2581-2588. [CrossRef] [PubMed] 
16. Ahn, M.-Y.; Filley, T.R.; Jafvert, C.T.; Nies, L.; Hua, I.; Bezares-Cruz, J. Photodegradation of decabromodiphenyl ether adsorbed onto clay minerals, metal oxides, and sediment. Environ. Sci. Technol. 2006, 40, 215-220. [CrossRef] [PubMed]

17. Chou, H.-L.; Chang, Y.-T.; Liao, Y.-F.; Lin, C.-H. Biodegradation of decabromodiphenyl ether (BDE-209) by bacterial mixed cultures in the soil/water system. Int. Biodeterior. Biodegrad. 2013, 85, 671-682. [CrossRef]

18. Yu, C.-C.; Chang, T.-C.; Liao, C.-S.; Chang, Y.-T. A comparison of the microbial community and functional genes present in free-living and soil particle-attached bacteria from an aerobic bioslurry reactor treating high-molecular-weight PAHs. Sustainability 2019, 11, 1088. [CrossRef]

19. Chou, H.-L.; Hwa, M.-Y.; Lee, Y.-C.; Chang, Y.-J.; Chang, Y.-T. Microbial degradation of decabromodiphenyl ether (DBDE) in soil slurry microcosms. Environ. Sci. Pollut. Res. 2016, 23, 5255-5267. [CrossRef]

20. Wu, H.; Zhao, H.; Wen, C.; Guo, Y.; Guo, J.; Xu, M.; Li, X. A comparative study of bacterial community structures in the sediments from brominated flame retardants contaminated river and noncontaminated reservoir. Afr. J. Microbiol. Res. 2012, 6, 3248-3260.

21. Liu, J.; He, X.; Lin, X.; Chen, W.; Zhou, Q.; Shu, W.; Huang, L. Ecological effects of combined pollution associated with e-waste recycling on the composition and diversity of soil microbial communities. Environ. Sci. Technol. 2015, 49, 6438-6447. [CrossRef]

22. Liu, J.; Chen, X.; Shu, H.; Lin, X.; Zhou, Q.; Bramryd, T.; Shu, W.; Huang, L. Microbial community structure and function in sediments from e-waste contaminated rivers at Guiyu area of China. Environ. Pollut. 2018, 235, 171-179. [CrossRef] [PubMed]

23. Liu, L.; Zhu, W.; Xiao, L.; Yang, L. Effect of decabromodiphenyl ether (BDE 209) and dibromodiphenyl ether (BDE 15) on soil microbial activity and bacterial community composition. J. Hazard. Mater. 2011, 186, 883-890. [CrossRef]

24. Chang, Y.T.; Lo, T.; Chou, H.-L.; Laio, Y.-F.; Lin, C.C.; Chen, H.-T. Anaerobic biodegradation of BDE-209-contaminated sediment by organic composts. Int. Biodeterior. Biodegrad. 2016, 113, 228-237. [CrossRef]

25. Shi, G.; Yin, H.; Ye, J.; Peng, H.; Li, J.; Luo, C. Aerobic biotransformation of decabromodiphenyl ether (PBDE-209) by Pseudomonas aeruginosa. Chemosphere 2013, 93, 1487-1493. [CrossRef] [PubMed]

26. Liu, Y.; Gong, A.-J.; Qiu, L.-N.; Li, J.-R.; Li, F.-K. Biodegradation of decabromodiphenyl ether (BDE-209) by crude enzyme extract from Pseudomonas aeruginosa. Int. J. Environ. Res. Public Health 2015, 12, 11829-11847. [CrossRef]

27. Zhang, S.; Xia, X.; Xia, N.; Wu, S.; Gao, F.; Zhou, W. Identification and biodegradation efficiency of a newly isolated 2,2',4,4'-tetrabromodiphenyl ether (BDE-47) aerobic degrading bacterial strain. Int. Biodeterior. Biodegrad. 2013, 76, 24-31. [CrossRef]

28. Xin, J.; Liu, X.; Liu, W.; Zheng, X.L. Aerobic transformation of BDE-47 by a Pseudomonas putida sp. strain TZ-1 Isolated from PBDEs-contaminated sediment. Bull. Environ. Contam. Toxicol. 2014, 93, 483-488. [CrossRef]

29. Lv, Y.; Li, L.; Chen, Y.; Tang, Z.; Hu, Y. Effects of glucose and biphenyl on aerobic cometabolism of polybrominated diphenyl ethers by Pseudomonas putida: Kinetics and degradation mechanism. Int. Biodeterior. Biodegrad. 2016, 108, 76-84. [CrossRef]

30. Xu, M.; Chen, X.; Qiu, M.; Zeng, X.; Xu, J.; Deng, D.; Sun, G.; Li, X.; Guo, J. Bar-coded pyrosequencing reveals the responses of PBDE-degrading microbial communities to electron donor amendments. PLoS ONE 2012, 7, e30439. [CrossRef]

31. Chen, X.; Chen, G.; Qiu, M.; Sun, G.; Guo, J.; Xu, M. Synergistic degradation of deca-BDE by an enrichment culture and zero-Valent iron. Environ. Sci. Pollut. Res. 2014, 21, 7856-7862. [CrossRef]

32. Schmidt, S.; Wittich, R.M.; Erdmann, D.; Wilkes, H.; Francke, W.; Fortnagel, P. Biodegradation of diphenyl ether and its monohalogenated derivatives by Sphingomonas sp. strain SS3. Appl. Environ. Microbiol. 1992, 58, 2744-2750. [PubMed]

33. Schmidt, S.; Fortnagel, P.; Wittich, R.M. Biodegradation and transformation of 4,4'-dihalodiphenyl and 2,4-dihalodiphenyl ethers by Sphingomonas sp. strain SS33. Appl. Environ. Microbiol. 1993, 59, 3931-3933. [PubMed]

34. Kim, Y.M.; Nam, I.H.; Murugesan, K.; Schnidt, S.; Crowley, D.E.; Chang, Y.S. Biodegradation of diphenyl ether and transformation of selected brominated congeners by Sphingomonas sp. PH-07. Appl. Microbiol. Biotechnl. 2007, 77, 187-194. [CrossRef]

35. Kim, Y.M.; Murugesan, K.; Chang, Y.Y.; Kim, E.J.; Chang, Y.S. Degradation of polybrominated diphenyl ethers by a sequential treatment with nanoscale zero valent iron and aerobic biodegradation. J. Chem. Technol. Biotechnol. 2012, 87, 216-224. [CrossRef] 
36. Tian, R.M.; Lee, O.O.; Wang, Y.; Cai, L.; Bougouffa, S.; Chiu, J.M.; Wu, R.S.; Qian, P.Y. Effect of polybrominated diphenyl ether (PBDE) treatment on the composition and function of the bacterial community in the sponge Haliclona cymaeformis. Front. Microbiol. 2015, 5, 799. [CrossRef] [PubMed]

37. Shih, Y.-H.; Chou, H.-L.; Peng, Y.-H. Microbial degradation of 4-monobrominated diphenyl ether with anaerobic sludge. J. Hazard. Mater. 2012, 213, 341-346. [CrossRef] [PubMed]

38. Kielak, A.M.; Barreto, C.C.; Kowalchuk, G.A.; van Veen, J.A.; Kuramae, E.E. The ecology of Acidobacteria: Moving beyond genes and genomes. Front. Microbiol. 2016, 7, 744. [CrossRef]

39. Goosen, N.; Moolenaar, G.F. Repair of UV damage in bacteria. DNA Repair 2008, 7, 353-379. [CrossRef]

40. Zhang, S.; Wang, Q.; Wan, R.; Xie, S. Changes in bacterial community of anthracene bioremediation in municipal solid waste composting soil. J. Zhejiang Univ. Sci. B 2011, 12, 760-768. [CrossRef]

41. Agogué, H.; Joux, F.; Obernosterer, I.; Lebaron, P. Resistance of marine bacterioneuston to solar radiation. Appl. Environ. Microbiol. 2005, 71, 5282-5289. [CrossRef]

42. Liu, H.; Yan, J.; Wang, Q.; Karlson, U.G.; Zou, G.; Yuan, Z. Biodegradation of methyl tert-butyl ether by enriched bacterial culture. Curr. Microbiol. 2009, 59, 30-34. [CrossRef] [PubMed]

43. Romanovskaia, V.A.; Rokitko, P.V.; Malashenko, IuR. Unique properties of highly radioresistant bacteria. Mikrobiol. Z. 2000, 62, 40-63. [PubMed]

44. Jolivet, E.; L'Haridon, S.; Corre, E.; Forterre, P.; Prieur, D. Thermococcus gammatolerans sp. nov., a hyperthermophilic archaeon from a deep-sea hydrothermal vent that resists ionizing radiation. Int. J. Syst. Evol. Microbiol. 2003, 53, 847-851. [CrossRef] [PubMed]

45. Yu, J.; Liu, Q.; Liu, L.; Chen, J. Cloning and characterization of dichloromethane dehalogenase from Methylobacterium rhodesianum for dichloromethane degradation. Bioremediation J. 2017, 21, 71-80. [CrossRef]

46. Liang, S.H.; Liu, J.K.; Lee, K.H.; Kuo, Y.C.; Kao, C.M. Use of specific gene analysis to assess the effectiveness of surfactant-enhanced trichloroethylene cometabolism. J. Hazard. Mater. 2011, 198, 323-330. [CrossRef]

47. Lee, J.-J.; Kang, M.-S.; Kim, G.; Lee, C.; Lim, S.; Lee, J.; Roh, S.H.; Kang, H.; Ha, J.M.; Bae, S.; et al. Flavisolibacter tropicus sp. nov., isolated from tropical soil. Int. J. Syst. Evol. Microbiol. 2016, 66, 3413-3419. [CrossRef]

48. Kim, M.; Sohn, E.-H.; Jung, H.-Y.; Srinivasan, S. Complete genome sequence of Flavisolibacter tropicus, a radiation resistant bacterium. Korean J. Microbiol. 2018, 54, 87-89.

49. Thelusmond, J.-R.; Strathmarin, T.J.; Cupples, A.M. The identification of carbamazepine biodegrading phylotypes and phylotypes sensitive to carbamazepine exposure in two soil microbial communities. Sci. Total Environ. 2016, 571, 1241-1252. [CrossRef]

50. Lin, Z.; Zhen, Z.; Ren, L.; Yang, J.; Luo, C.; Zhong, L.; Hu, H.; Liang, Y.; Li, Y.; Zhang, D. Effects of two ecological earthworm species on atrazine degradation performance and bacterial community structure in red soil. Chemosphere 2018, 196, 467-475. [CrossRef]

51. Hemkemeyer, M.; Dohrmann, A.B.; Christensen, B.T.; Tebbe, C.C. Bacterial preferences for specific soil particle size fractions revealed by community analyses. Front. Microbiol. 2018, 9, 149. [CrossRef]

52. Sessitsch, A.; Weilharter, A.; Gerzabek, M.H.; Kirchmann, H.; Kandeler, E. Microbial population structures in soil particle size fractions of a long-term fertilizer field experiment. Appl. Environ. Microbiol. 2001, 67, 4215-4224. [CrossRef] [PubMed]

53. Franzluebbers, A.J. Soil organic matter stratification ratio as an indicator of soil quality. Soil Tillage Res. 2002, 66, 95-106. [CrossRef]

54. Yan, F.; McBratney, A.B.; Copeland, L. Functional substrate biodiversity of cultivated and uncultivated a horizons of vertisols in NW New South Wales. Geoderma 2000, 96, 321-343. [CrossRef]

55. Tiquia, S.M.; Lloyd, J.; Herms, D.A.; Hoitink, H.A.J.; Michel, F.C., Jr. Effects of mulching and fertilization on soil nutrients, microbial activity and rhizosphere bacterial community structure determined by analysis of TRFLPs of PCR-amplified 16S rRNA genes. Appl. Soil Ecol. 2002, 21, 31-48. [CrossRef]

56. Liu, T.X.; Ji, X.E. Effect of crop straw burning on soil organic matter and soil microbes. Soils 2003, 4, 347-348, ISSN 0253-9829.

(C) 2019 by the authors. Licensee MDPI, Basel, Switzerland. This article is an open access article distributed under the terms and conditions of the Creative Commons Attribution (CC BY) license (http://creativecommons.org/licenses/by/4.0/). 